\title{
ARTIGO - PAULO FREIRE: OUTRO PARADIGMA PEDAGÓGICO?
}

\author{
MIGUEL G. ARROYO ${ }^{*}$ \\ ORCID: https://orcid.org/0000-0002-3702-2057
}

RESUMO: O texto lembra os 50 anos da publicação da Pedagogia do Oprimido de Paulo Freire. Que interrogações chegam hoje dos oprimidos para o pensamento pedagógico? A Pedagogia do Oprimido revela que estes são novos tempos de opressão. As opressões aumentam, com requintes políticos. Os oprimidos repõem outro paradigma de formação humana, outro paradigma de humano-inumano, de desumanização-humanização. $\mathrm{O}$ aumento da pobreza extrema e do desemprego faz crescer o número de oprimidos desumanizados. Os oprimidos se sabem roubados em sua humanidade e se sabem ameaçados da violência do Estado. Há violência do Estado e de seus órgãos de justiça e segurança contra jovens e adolescentes exterminados nas periferias urbanas, violências contra militantes em lutas por direitos. Mas os oprimidos, em seus movimentos sociais, resistem, afirmam-se humanos e apontam para outro paradigma pedagógico.

Palavras-chave: Opressão. Formação humana. Paradigma pedagógico.

\section{ARTICLE - PAULO FREIRE: ANOTHER PEDAGOGICAL PARADIGM?}

ABSTRACT: The text reminds us of the 50th anniversary of Paulo Freire's Pedagogia do Oprimido. What questions from the oppressed reach pedagogical thought today? The Pedagogia do Oprimido reveals that we are in new times of oppression. The oppressions increase and with political refinements. The oppressed replace another paradigm of human formation. Another paradigm of human-inhuman; dehumanization-humanization. The growth of extreme poverty and unemployment increases the number of dehumanized oppressed. The humanity is robbed from the oppressed that are known to be threatened by the violence of the State. There is violence of the State and its organs of justice and security against young people and adolescents exterminated in the urban peripheries, violence against militants that are fighting for rights. But the oppressed, in their social movements, resist, claim their own humanity and point another pedagogical paradigm. Keywords: Oppression. Human formation. Pedagogical paradigm.

'Universidade Federal de Minas Gerais, Faculdade de Educação, Belo Horizonte, MG, Brasil.

"Doutor em Educação pela Stanford University. Professor Titular Emérito da Faculdade de Educação da Universidade Federal de Minas Gerais (UFMG). E-mail:<g.arroyo@uol.com.br >. 


\section{PAULO FREIRE: UN AUTRE PARADIGME PEDAGOGIQUE?}

RÉSUMÉ: Le texte nous rappelle le 50e anniversaire de la pédagogie de l'opprimé de Paulo Freire. Quelles questions des opprimés atteignent aujourd'hui la pensée pédagogique? La pédagogie des opprimés reprend que nous sommes dans une nouvelle ère d'oppression. Les oppressions augmentent et avec des raffinements politiques. Les opprimés remplacent un autre paradigme de la formation humaine. Un autre paradigme humaininhumain; déshumanisation-humanisation. L'augmentation de la pauvreté extrême et du chômage augmente le nombre d'oppresseurs déshumanisés. Les opprimés sont dépouillés de leur humanité et sont connus pour être menacés par la violence de l'État. Violence de l'Etat et de ses organes de justice et de sécurité contre les jeunes et les adolescents exterminés dans les périphéries urbaines. Violence contre les militants dans les luttes pour les droits. Mais les opprimés dans leurs mouvements sociaux résistent, revendiquent des êtres humains et désignent un autre paradigme pédagogique.

Mots-clés: Oppression; Formation humaine; Paradigme pédagogique

O Congresso ${ }^{1}$ propõe que nos voltemos para o pensamento pedagógico de Paulo Freire. Nos tempos atuais, de que pensamento pedagógico devemos nos aproximar? Penso que, tendo em vista o Golpe e as vivências de opressões políticas sociais tão próximas às experienciadas no contexto em que Paulo Freire refletiu sobre a opressão, somos obrigados a nos acercar da Pedagogia do Oprimido.

Retomaro pensamento de Paulo Freire em tempos de requintados processos de opressão é uma afirmação de que temos consciência da urgência de formar docentes-educadores capazes de entender a brutal tirania de que são vítimas milhões de educandos nas escolas públicas e na EJA. Deixemo-nos interrogar por Paulo Freire, pelos oprimidos.

Que interrogações dos oprimidos Paulo Freire traz para o pensamento pedagógico? Ele proporciona questionamentos sobre políticas que conferem nova radicalização ética-política ao pensamento pedagógico, à educação.

Interrogações de "sujeitos" no mundo sendo-não-sendo no mundo, na economia, na política, na educação. Paulo Freire continua propondo que privilegiemos os sujeitos. Interroga-nos sobre qual o lugar, a centralidade dos indivíduos e de suas perguntas sobre sernão-ser, no mundo, no pensamento pedagógico, nas políticas, nos Currículos de Formação? 
Paulo Freire prioriza ver, reconhecer, os Outros como sujeitos de voz, sujeitos de saberes, culturas, consciência. Propõe uma visão dos Outros de extrema radicalidade política, que se contrapõe a uma História de tentativas brutais de reprimir sua voz, suas presenças na política, na história, na cultura e até na pedagogia.

Mas como vê-los? Paulo os vê como oprimidos que nos interrogam a vê-los como oprimidos. E sugere superar um pensamento político e pedagógico que oculta a história como uma relação opressores-oprimidos.

\section{NOVOS-VELHOS TEMPOS DE OPRESSÃO}

A Pedagogia do Oprimido retoma atualidade. Por quê? Porque a opressão continua, os oprimidos aumentaram, os processos de opressão não só se repetem, mas se aperfeiçoam em refinamentos. Os oprimidos são decretados criminosos. São extermináveis como militantes e até como jovens, adolescentes e crianças.

Estamos em tempos de golpes ditatoriais tão próximos aos que, nos anos 60, provocaram Paulo a escrever a Pedagogia do Oprimido. Seu pensamento é atual porque a opressão é atual. As violências de Estado são atuais e requintadas contra os mesmos coletivos: os trabalhadores e seus direitos; os jovens pobres, negros, periféricos e seus extermínios; os movimentos sociais por direito à terra, ao teto, ao trabalho, à renda, à saúde, à educação, por identidades de coletivos reprimidos, exterminados. São tempos de anulação política das formas de resistência de classe dos oprimidos. São tempos de jogar milhões ao desemprego, à ausência de direitos do trabalho, à falta de um futuro previdenciário; tempos de concentração da renda e da terra em mãos de poucos e de aumento da miséria, da pobreza, dos sem-renda, dos sem-terra, dos sem-teto, dos sem-trabalho. Tempos de aumento dos oprimidos, de radicalização das formas de opressão, tornam de extrema atualidade Paulo Freire e a Pedagogia do Oprimido.

Sempre que os processos de opressão são repostos e sempre que os oprimidos aumentam, somos obrigados a repor o pensamento de Paulo Freire. Aprender a olhar esses movimentos com o olhar de Paulo Freire. Sobretudo, sempre que os oprimidos resistem a toda forma de opressão, resistem por libertação, somos obrigados a tentar entender com que pedagogias se libertam, humanizam-se.

O pensamento político-pedagógico é obrigado a tentar entender que os oprimidos continuam se afirmando sujeitos de outras 
pedagogias. É impelido a compreender que existem outras pedagogias que interrogam, desconstroem as pedagogias hegemônicas, que se julgam únicas, universais.

São questões obrigatórias para a pedagogia, para a formação de docentes-educadores/as: com que paradigma pedagógico entender e acompanhar os milhões que vão às escolas públicas, sobretudo os que voltam à EJA, vivenciam desde crianças opressões sociais, políticas, culturais - desemprego, pobreza extrema, desterritorialização, ausência de lugar digno de viver e procura de um lugar -, e sobrevivem com ameaças de extermínio nas prisões e até nos centros socioeducativos? Que currículos de formação de docentes-educadores podem entender e acompanhar esses educandos nos processos de desumanização, de roubo de suas humanidades?

Além disso, indago: com que pensamento pedagógico as faculdades de educação prepararão profissionais nas Artes pedagógicas de recuperar as humanidades roubadas de milhões de crianças, adolescentes, jovens e adultos que resistem, lutam por se libertar da opressão? Diante das radicais formas políticas de opressão, de extermínios, como decodificar a radicalidade da Pedagogia do Oprimido? É preciso reconhecer que dos Oprimidos vem outro paradigma pedagógico. Eles não vêm suplicar piedosas pedagogias de como ensiná-los, incluí-los, letrá-los, conscientizá-los.

Retomar o pensamento de Paulo Freire será uma oportunidade para colocar-nos uma interrogação radical: dos oprimidos e de suas Pedagogias vem outro paradigma pedagógico? Sugiro que destaquemos que de Paulo Freire vem a urgência político-pedagógica de reconhecer de modo afirmativo essa questão.

Pretendo trabalhar essa hipótese em torno dos seguintes itens: $1^{\circ}$.) Os oprimidos repõem outro paradigma de formação humana. $2^{\circ}$.) Os oprimidos desconstroem o paradigma de humano-in-humano. $3^{\circ}$.) Os oprimidos repõem o paradigma de desumanização-humanização. $4^{\mathrm{o}}$.) Os oprimidos se sabem roubados em sua humanidade.

$5^{\circ}$.) Os oprimidos se sabem ameaçados das violências de Estado.

$6^{\circ}$.) Os oprimidos resistem, afirmam-se humanos.

$7^{\circ}$.) Outro paradigma de formação de docentes-educadores?

\section{$1^{0}$.) OS OPRIMIDOS REPÕEM OUTRO PARADIGMA DE FORMAÇÃO HUMANA}

O paradigma que persiste no pensamento pedagógico desde a Paideia se propõe acompanhar os processos de formação humana 
desde a infância, a acompanhar apenas os humanos reconhecidos como educáveis, humanizáveis. O pensamento pedagógico, desde suas origens, defronta-se com uma dúvida: a que grupos sociais e políticos reconhecer como humanos, educáveis, humanizáveis? A Paideia reconhece somente os homens livres, pensantes, dirigentes da Polis. A crença na educabilidade, humanidade, não se aplica aos Outros, aos trabalhadores manuais, às mulheres, aos escravos. A pedagogia ilustrada só identifica como humanos aqueles que se atrevem a pensar e a ser éticos orientados pelo bem pensar. Os humanos homens são de bem porque são bem pensantes.

Portanto, uma marca persistente no paradigma pedagógico hegemônico é: distinguir e acompanhar os processos de formação humana dos grupos sociais, políticos, culturais reconhecidos como humanos, educáveis, humanizáveis. Essa concepção é seguida de uma persistente crença segregadora: nem todos são racionais, éticos, educáveis, humanizáveis a ponto de merecer o reconhecimento da Pedagogia, de ser contemplados pelos movimentos de formação humana (ARROYO, 2015). Tal pensamento assumiu uma postura de descompromisso político, ético, pedagógico com a humanização dos Outros, dos oprimidos, por não os reconhecer humanizáveis, educáveis, passíveis de formação humana.

Paulo Freire contradiz esse pensamento pedagógico segregador, identifica-se como educador, em defesa da formação humana ao longo de todos seus escritos e de suas práticas. Não pensa os oprimidos como não humanizáveis, mas como humanos já. Por que tanta dificuldade de Paulo Freire ser reconhecido nas análises do pensamento pedagógico? Porque ele se contrapõe a essa marca tão persistente do paradigma pedagógico hegemônico e reconhece que os Outros são educáveis, humanizáveis, sujeitos de pedagogias outras de formação humana. Contrapõe-se a segregar os Outros, os grupos sociais pobres, os trabalhadores, os oprimidos como primitivos, irracionais, sem saberes nem valores, sem leituras de mundo e de si no mundo, sem consciência política, sub-humanos, in-educáveis, in-humanizáveis.

Paulo Freire, ao conceber os oprimidos como sujeitos de processos, de pedagogias de formação humana, leva sua crítica política, ética, pedagógica a um dos pontos nucleares do paradigma hegemônico de formação humana. Não critica o pensamento pedagógico apenas por ter esquecido sua responsabilidade de acompanhar e entender também os processos de formação humana dos Outros. Sua crítica a esse paradigma é ele ter julgado e segregado os Outros, os oprimidos, deixando-os à margem da educação a que a pedagogia é chamada a compreender e acompanhar. 
Reconhecer os Outros, os oprimidos, como sujeitos de formação humana representa outro paradigma de formação humana. Mas Paulo vai além: denuncia que os oprimidos são condenados a processos históricos brutais de de-formação humana.

Que exigências traz esse condená-los a processos de desumanização para os cursos de formação de educadores, educadoras, docentes de crianças, adolescentes nas escolas, de jovens-adultos na EJA jogados pela sociedade em processos de de-formação humana? Os currículos de formação se defrontam com carências de teorias sobre deformação humana desses educandos oprimidos. $\mathrm{O}$ pensamento pedagógico tem acumulado mais teoria sobre processos de formação humana, de desenvolvimento humano do que teorias sobre a brutal deformação humana.

Dominar os saberes acumulados sobre desenvolvimento humanocapacitará os educadores-docentes para entendereacompanhar os brutais processos de deformação, negação do desenvolvimento humano de que são vítimas os educandos oprimidos? Outro paradigma de formação-de-formação humana exige centralidade na formação de profissionais da educação dos oprimidos.

\section{$2^{\circ}$.) OS OPRIMIDOS DESCONSTROEM O PARADIGMA DE HUMANO-IN-HUMANO}

O que levou o pensamento pedagógico a segregar os Outros como não sujeitos da Pedagogia, dos processos de formação humana? Pensá-los sem os atributos de humanidade, educabilidadesem razão, sem valores, sem cultura, sem consciência política -, vêlos como subcidadãos, sub-humanos? Boaventura de Sousa Santos (2013, p. 76) nos lembra de que "a tensão entre humano-não humano convive com a ideia de uma deficiência originária de humanidade, a ideia de que nem todos os seres com o fenótipo humano são plenamente humanos". Anibal Quijano (2009) rememora que os povos originários nas Américas foram jogados à pré-história da condição humana - em estado de natureza, - tornando-os um mito metafísico, uma deficiência no ser humano.

Esse é um traço persistente estruturante do paradigma pedagógico hegemônico: a polarização entre cidadãos-sub-cidadãos, humanos-in-humanos e a atitude de delegar à educação a tentativa de incluir os subcidadãos na cidadania, os in-humanos no parâmetro único de humanidade. Um reconhecimento de cidadania e de humanidade condicionado à superação dos percursos de educação para sair do estado de natureza. 
O pensamento pedagógico traz as marcas do paradigma segregador de humano-in-humano, cidadão-sub-cidadão, tão presente e persistente no pensamento social, político hegemônico. Nem todos são dignos de serem nomeados "cidadãos da Polis" por não merecerem ser reconhecidos como humanos. A república grega e todas as repúblicas investiram mais em formar os reconhecidos cidadãos do que os decretados subcidadãos. O pensamento político-pedagógico tem concentrado mais saberes, políticas, diretrizes para humanizar os já reconhecidos como humanos do que para educar os segregados como in-humanos. Para os segregados como sub-cidadãos, in-humanos, há promessas de inclusão pela educação, pela escolarização com promessas de reintegração na sociedade, se reeducados nos sistemas socioeducativos. Até o sonho do ensino progressista carrega essa dicotomia: educação "para" a cidadania, "para" a formação humana dos grupos sociais segregados como ainda não cidadãos, não humanos.

Definir um protótipo único, universal, de Humano tem servido como parâmetro de segregação dos Outros como in-humanos. Esse protótipo de humano elevado à condição de absoluto vem desde a Paideia e é reforçado pelos humanismos renascentista e ilustrado e, de maneira radical, pela empreitada colonizadora. Paulo Freire aprende com os oprimidos que não apenas se afirmam humanos, mas se contrapõem ao paradigma de humano em nome do qual são decretados não-humanos.

Podemos reconhecer que a pedagogia colonizadora tão persistente nas Américas é uma das experiências de radicalização desse paradigma segregador de humano, in-humano. A história de nosso pensamento pedagógico se tem alimentado dessa segregação dos Outros como in-humanos, desde a empreitada educativa colonizadora, e como subcidadãos, na vertente educadora republicana e democrática. O pensamento colonial, para legitimar a apropriação da terra e a exploração escravista do trabalho, decretou os povos originários e os negros como sem-alma, in-humanos. Esse traço persiste na classificação social, étnica, racial, no pensamento social, político, cultural, pedagógico.

A crítica De-Colonial vem mostrando como se configurou o sistema de classificação social, étnica, racial em nossa história. Essa crítica levanta questões radicais para a pedagogia: que papel teve a pedagogia e continua tendo na legitimação desse sistema de classificação-segregação social, humana? Com que visões humanas e pedagógicas dos grupos sociais, étnicos e raciais se legitima conformar identidades coletivas inferiorizadas como in-humanos? 
Aníbal Quijano (2009), sociólogo latino-americano, defende que aqui se configurou um sistema de classificação social, racial, étnica da população do mundo (não apenas da periferia colonizada), tipologia, expressão do poder-saber que o capitalismo torna mundial. A diversidade étnico-racial convertida em padrão de superioridade/ inferioridade humana, intelectual, cultural, moral tem sido, em nossa história, um dos mecanismos pedagógicos mais perversos e persistentes.

No livro Outros sujeitos, outraspedagogias (ARROYO, 2012,p. 153), pergunto-me como as concepções pedagógicas que se legitimaram e foram elaboradas na construção desse sistema de classificação social, étnica, racial e nesse padrão de dominação-subalternizaçãoinferiorização produziram concepções, teorias e práticas de como “educar” para legitimar essa classificação-inferiorização social e racial. A pedagogia colonial, republicana e moderna se constitui atrelada a esse sistema classificatório e legitima as relações de poder-dominaçãosubalternização que se formam a partir dos padrões de apropriaçãoexpropriação da terra, dos territórios, do modelo de trabalho escravo, explorador, alienante. A subalternização-inferiorização social, étnica, racial, cultural e pedagógica determinante do projeto pedagógico hegemônico aqui gestado direciona-se para cada um desses coletivos na colonialidade e na pós-colonialidade republicana e democrática.

Paulo Freire se contrapõe a esse paradigma de humanoin-humano que vem das origens da Pedagogia e se radicaliza na experiência pedagógica e política da colonização e do poder-saber que o capitalismo torna mundial. Esse paradigma político-pedagógico segregador do nós como humanos e dos Outros como in-humanos é contra-argumentado por Paulo Freire com outro paradigma de humano: o educador reconhece os oprimidos, segregados em nossa história, à margem dos processos de humanização como humanos, sendo eles sujeitos não apenas de educabilidade, indivíduos humanizáveis pela educação de qualidade, mas também bumanos já. São sujeitos de humanidade, sujeitos de Pedagogias do Oprimido.

A Pedagogia do Oprimido é a síntese dessa contraposição política, ética, pedagógica ao segregador paradigma de humanoin-humano, in-humanizáveis, in-educáveis, que tem prevalecido no ponto de vista político-pedagógico antiético hegemônico. Paulo não se limita a uma crítica a essa perspectiva afirmando que os inhumanos são humanizáveis, vai além e compõe Outro paradigma ao identificar como "humanos já" os grupos sociais marcados com a mais antipedagógica e antiética segregação-opressão: o não 
reconhecimento como humanos, a manutenção deles na condição de in-humanos. Para Paulo, a opressão mais brutal é não ver um ser humano como humano e segregá-lo como in-humano. Essa é a crítica política radical de Paulo ao paradigma de humano-in-humano.

Essa radicalidade crítica-ética de Paulo Freire ao pensamento pedagógico hegemônico explica por que essa radicalidade é tão temida ou tem estado ausente no pensamento educacional, nos currículos de formação em Pedagogia e Licenciatura, nas políticas e diretrizes curriculares que persistem em prometer, oferecer aos oprimidos políticas de tirá-los da in-humanidade e incluí-los na humanidade, tirálos da subcidadania e incluí-los na cidadania, mas apenas se provarem ser educáveis-humanizáveis. Milhões de crianças-adolescentes e de jovens-adultos são reprovados nas escolas, na EJA, não tanto porque são iletrados, mas porque são avaliados como irracionais, com problemas de aprendizagem, porque são vistos como indisciplinados, violentos, sem valores, sem condutas de humanos. São reprovados porque são decretados in-humanizáveis, in-educáveis. São entregues a extremos controles nos centros socioeducativos e até entregues à justiça penal ou ao extermínio. Destaco uma pergunta incômoda que vem da Pedagogia do Oprimido: como a pedagogia vem reforçando, legitimando o paradigma de in-humano tão persistente em nossa história colonial, republicana, democrática?

Há questões para o pensamento pedagógico prevalecente nos currículos de formação de educadores-docentes: como trazeros embates de paradigmas de humanos-in-humanos para o núcleo de formação? Como docentes-educadores/as das infâncias-adolescências, dos jovens-adultos oprimidos ainda classificados na sociedade, na política, na cultura, nas políticas de segregação em centros socioeducativos, de extermínio como in-humanos têm direito a entender e a se contrapor a esse paradigma hegemônico de humano-in-humano.

Os próprios educandos que carregam às escolas, à EJA essa inferiorização como in-humanos têm direito a entender-se e conhecer esse paradigma político que os inferioriza como in-humanos. É direito deles saber-se para reforçar suas resistências por emancipação-libertação. Paulo insistia que os oprimidos têm direito a saber de si no mundo que os oprime na maior das opressões: segregá-los como in-humanos. Paulo Freire aponta o caminho: aprender com os próprios oprimidos que não se limitam a afirmar-se humanos, mas desconstroem o protótipo único de humano em nome do qual foram segregados como in-humanos. 


\section{3․) OS OPRIMIDOS REPÕEM O PARADIGMA DE DESUMANIZAC̣ÃO-HUMANIZAC̣̃̃O}

Os oprimidos reagem à dicotomia "humano-in-humano", não se aceitam na condição de in-humanos, mas ninguém melhor do que eles para ter consciência dos processos de desumanização a que a opressão social, étnica, racial, sexual os submete. Eles revelam que a contraposição "humanos-in-humanos" oculta outra contraposição mais radical: a relação opressores-oprimidos ou a classificação social que submete seres humanos a processos de desumanização.

Um dos conceitos mais presentes no pensamento pedagógico de Paulo Freire é a ideia de humanização-desumanização recuperando o olhar mais originário da pedagogia: humanizar, acompanhar desde a infância, o broto do humano, os processos de humanização. Mas Paulo adverte a pedagogia:

O problema de sua humanização, apesar de sempre dever haver sido o problema central, assume, hoje, caráter de preocupação iniludível. Constatar esta preocupação implica, indiscutivelmente, reconhecer a desumanização, não penas como viabilidade ontológica, mas como realidade histórica. (FREIRE, 1987, p. 29-30)

Se a desumanização é uma realidade histórica, não haverá como entender, reconstruir a história da própria educação como história da formação humana, sem reconstruir e entender a desumanização. Reconheçamos que essa é uma história esquecida, silenciada na própria narrativa da educação. Tal história de desumanização é relembrada pelos próprios oprimidos, vítimas de tantas estruturas, de tantas histórias de inferiorização guardadas em suas memórias.

Paulo nos leva além: a desumanização é uma produção de estruturas de sujeitos históricos. Há oprimidos porque há opressores, porque há estruturas sociais opressoras, desumanizadoras. Ele soma essa fala com o pensamento político, social, pedagógico socialista que vem destacando que as estruturas materiais de classe, de raça e de gênero produzem a desumanização. $\mathrm{O}$ mito da inferioridade ôntica dos indígenas, dos negros, dos pobres, dos trabalhadores manuais - categorizados como seres em estado de natureza - é uma produção histórica para apropriação de suas terras e exploração de sua força de trabalho.

Essa perspectiva se confronta com o pensamento e as políticas que continuam negando, ocultando, a produção histórica da desumanização-discriminação e responsabilizam os próprios grupos sociais, étnicos, raciais por sua condição de oprimidos, desumanizados. Essa visão ainda é muito persistente na própria cultura escolar segregadora dos milhões de oprimidos, desde a infância, condenados, reprovados, porque são responsabilizados 
pelas desumanizações com que a história os vitima, estigmatizandoos até como adolescentes em conflito com a lei.

Paulo vai além e lembra que todo processo histórico de humanização esteve sempre acompanhado de brutais dinâmicas de desumanização. O projeto colonial de educação dos povos indígenas, dos negros escravizados esteve acompanhado de violentos extermínios, de expropriação de suas terras, de suas crenças, de suas culturas e identidades. O projeto educativo-cultural colonial é acompanhado de violentos culturicídios, desumanizantes. Walter Benjamin (1994) nos lembra de que todo projeto cultural tem sido acompanhado de barbárie.

Paulo Freire lembra à pedagogia que, se o problema da humanização deve ser central, éiniludível reconhecer a desumanização não apenas como uma viabilidade ontológica, mas como realidade constituinte de nossa história social, política, cultural, pedagógica. Com sua análise, Freire faz uma crítica radical ao pensamento pedagógico hegemônico: considerar como sua função histórica apenas entender e acompanhar os processos de humanização, ignorando a produção histórica de desumanização. Dessa crítica, chega uma pergunta desafiante para o pensamento pedagógico hegemônico: este assume ou não a desumanização como uma produção histórica? Por que não tem assumido com centralidade entender os processos históricos de desumanização a que foram e continuam submetidos os grupos sociais, étnicos, raciais, sexuais, os oprimidos porque decretados onticamente inferiores em humanidade?

Desde a Paideia, poucas teorias sobre os processos de desumanização foram acumuladas. Nem nos humanismos pedagógicos renascentistas, nem nos ilustrados, nem nos republicanos teve centralidade entender essas construções históricas de desumanização para as quais Paulo Freire nos chama a atenção. Os docenteseducadores de crianças, adolescentes e jovens-adultos submetidos a processos de desumanização experimentam essas lacunas, pois poucos saberes acumularam nos cursos de formação para entender esses processos que os educandos levam às escolas, à EJA.

Paulo provoca o pensamento pedagógico e seus profissionais a entenderem mais, a formularem e acumularem teorias sobre os processos históricos não apenas de humanização, mas de desumanização. Reconhecer que a desumanização é uma realidade histórica iniludível. Logo, é uma exigência histórica iniludível para os profissionais da educação dos grupos sociais que padecem a opressãodesumanização entender mais os processos de desumanização.

Aos currículos de formação chega uma questão central: 
formam profissionais capazes de entender, acompanhar educandos vitimados por processos tão brutais de desumanização? Entender esses processos exige outro pensamento pedagógico, outra formação, outros saberes, outros profissionais, outros currículos de Pedagogia e de Licenciatura, nos quais tenha centralidade entender as vivências de desumanização que milhões de educandos padecem.

\section{$4^{\circ}$.) OS OPRIMIDOS SE SABEM ROUBADOS EM SUA HUMANIDADE}

O pensamento social, político, pedagógico, quando reconhece a desumanização dos Outros como realidade, constrói suas explicações: a desumanização é uma produção dos próprios grupos sociais segregados como in-humanos. Aníbal Quijano (2009) nos lembra que o pensamento educativo político colonial assim pensou os povos originários, indígenas, negros, não em estado de humanidade, mas de natureza, logo, incapazes de participar na produção intelectual, cultural, moral da humanidade. Essa inferiorização ôntica os responsabiliza por sua desumanização.

Podemos constatar outra explicação persistente que vem desde a Paideia: as funções de direção, de participação na Polis, de domínio da cultura, do raciocínio, dos trabalhos intelectuais que humanizam seus sujeitos. Assim, os trabalhos servis, manuais, de produção da vida, de criação, procriação desumanizam os grupos sociais, sexuais, raciais que os exercem. À educação são encomendadas as tarefas de instruir e, sobretudo, moralizar os sem valores, sem racionalidade, sem consciência, para sair da condição de desumanização. É encomendada ainda a função de formá-los para outros trabalhos, outras ocupações menos desumanizantes. Desse modo, é feita a educação dos outros para a cidadania, para o trabalho. Essas são funções esperadas da educação para superar a desumanização, funções que persistem na cultura pedagógica escolar, docente, avaliativa, e que tentam legitimar os padrões sexistas, classistas, racistas de trabalho, de poder, de justiça, de renda, de proteção ou de extermínio.

Paulo Freire se contrapõe de maneira radical a essas explicações que culpam os oprimidos pela desumanização que os oprime. Ele vê a humanização e a desumanização dentro da história, em um contexto real, objetivo:

Se ambas são possibilidades na história só a humanização é a vocação dos homens, vocação negada, mas também afirmada na própria negação. Vocação de humanização negada na injustiça, na exploração, na opressão, na violência dos opressores, mas afirmada no anseio de liberdade, de justiça, de luta dos oprimidos pela recuperação de sua humanidade roubada. (FREIRE, 1987, p. 30) 
PauloFreire não responsabiliza os oprimidos pela desumanização de que são vítimas, responsabiliza as injustiças, a exploração, a opressão, a violência dos opressores. Coloca uma interrogação radical, ética, política para o pensamento social, político, pedagógico: continuar vendo os pobres trabalhadores, que pressionam por direitos, por educação, por trabalho e por vida justa como responsáveis pela desumanização de que padecem, ou vê-los e tratá-los como vítimas das injustiças, da exploração e da violência dos opressores?

Interrogações radicais para os currículos de formação e para a cultura escolar e docente são: os profissionais formados nos cursos de Pedagogia e de Licenciatura para trabalhar com crianças, adolescentes, jovens-adultos condenados a processos de desumanização que compreensão recebem e levam desses processos e dos educandos oprimidos? Com que Artes pedagógicas são formados para trabalhar vidas em processos de desumanização? Os currículos das escolas públicas, sobretudo, e de EJA, garantem o direito dos oprimidos a entender esses processos históricos que os desumanizam? Os saberes escolares docentes continuarão responsabilizando os desumanizados pela desumanização que padecem?

Paulo Freire desafia a pedagogia, a docência, o pensamento pedagógico, as teorias do desenvolvimento humano a entender o que há de mais radical nos processos de opressão-desumanização: roubar Humanidades, roubar as possibilidades de ser humano, de ser mais. Esses sujeitos são roubados na vocação ontológica de serem humanos. Os docentes-educadores de milhões de crianças, adolescentes, jovens-adultos oprimidos receberam teorias e Artes para entender e acompanhar processos tão complexos de roubo de suas humanidades? Com esses desafios radicais para a teoria pedagógica, os próprios docentes-educadores tornam-se conscientes de lidar com humanidades roubadas desde a infância; aprendem que as Imagens de infância - flor, primavera, esperança se quebraram (ARROYO, 2004). Tais processos de desenvolvimento humano quebrados exigem outras teorias de formação humana.

\section{$5^{\circ}$. ) OS OPRIMIDOS SE SABEM AMEAÇADOS DAS VIOLÊNCIAS DE ESTADO}

Estamos em tempos dos oprimidos; jovens, adolescentes, militantes precisam saber-se ameaçados das violências de Estado. Houve uma radicalização política da opressão. Novos tempos ainda mais radicais se instauram: as velhas-novas formas de opressão, de roubo de humanidades se intensificaram em processos de execução, de extermínio social, de classe, de raça, de milhares de jovensadolescentes-crianças, militantes, negros, mulheres, como Marielle. 
Saber-se ameaçados de morte desde a infância-adolescênciajuventude porque são trabalhadores militantes pobres, periféricos, negros ou porque são militantes mulheres em lutas por direitos acrescenta uma nova radicalidade à opressão, que exige um olhar pedagógico mais radical. É uma radicalidade política nova, porque as ameaças de extermínios, mortes vêm das forças da ordem, com a cobertura da justiça, do Estado, dos poderes instituídos. Acontecem violências contra adolescentes nos centros socioeducativos que os privam de liberdade e violências, extermínios de jovens, em sua maioria negros, nos fins de semana ou nas prisões. A justificativa dos governantes: "nenhum dos mortos era um santo". Volta a visão de serem in-humanos que não merecem nem o direito à vida $\mathrm{e}$ muito menos o direito à educação.

São tempos de violências políticas, de Estado, tempos de lembrar que o Estado tem donos, a justiça tem donos, a terra tem dons, a renda do trabalho tem donos. O poder tem donos. As políticas de saúde e de educação têm donos. São tempos de aprender a duvidar até do Estado de direitos e de justiça. São tempos de mudar de estratégias de luta: de não poder mais proclamar "Educação é direito de todo cidadão, é dever do Estado!”. De que Estado? São tempos de não esperar justiça da justiça do Estado, de não esperar nem o direito à vida de um Estado e de seus aparelhos que exterminam.

Paulo Freire foi vítima das violências de Estado, foi exilado e se contrapôs às violências políticas de que os oprimidos são vítimas. Experimentou e denunciou a negação política da ética: "Impossível fazer política sem ética" (FREIRE, 1987). Paulo não apenas denunciou e se contrapôs à omissão criminosa das políticas do Estado com os direitos dos oprimidos. Defendeu a construção de outro Estado e se empenhou nela. Os movimentos sociais, o movimento infantojuvenil lutam por outro Estado, reagindo às violências de Estado que os vitimam e até os exterminam em massacres das forças do Estado. Que indagações vêm para o pensamento pedagógico?

Exterminar vidas é mais radical ainda do que roubar humanidades. Há motivos para o pensamento político, pedagógico hegemônico ignorar esses extermínios tão brutais. Há motivos para ignorar o Outro pensamento que Paulo Freire reforça, motivos para não reconhecer Paulo Freire patrono da Educação: o Estado e seus aparelhos passaram a ser os opressores. As violências de Estado privam adolescentes de liberdade e até acabam com vidas. Os educadores aprendem no conviver com educandos roubados em suas humanidades e até exterminados, aprendem que as formas de 
opressão se radicalizaram nos extermínios. Haverá lugar nos currículos de formação para que os educadores, educadoras entendam os educandos roubados em suas humanidades, que se sabem ameaçados de extermínios? Há algo mais opressor para um ser humano do que, desde criança, roubar-lhe sua humanidade e proibi-lo de ser, de viver?

Estamos em tempos em que a longa experiência histórica de opressão, de produção e de manutenção de estruturas opressoras se tornou uma experiência totalitária de Estado. A opressão estruturante das políticas de apropriação da terra, do solo, da renda legitimam o Estado; a justiça decreta a reintegração da posse e legitima a morte, o extermínio de militantes em lutas por direito à terra, ao teto, à vida.

A opressão não é apenas desumanização da violência de ser condenados a viver na miséria, na fome, em lugares inumanos nem a vivência da opressão é apenas não ser do mundo comum, público, da cidadania, dos direitos políticos, cidadãos. Institucionalizar a opressão em nível das violências de Estado radicaliza-a em nível de extermínio. Rouba-se mais do que a possibilidade de ser-mais. Roubam-se possiblidades de viver. Dados mostram que jovens, adolescentes e até crianças são um dos grupos vítimas dos extermínios e das violências de Estado.

O Mapa da Violência destaca que 29 jovens-adolescentes são mortos por dia, que o número de mortes de adolescentes revela que o risco de morte nesse tempo humano é maior do que na população geral. São os jovens-adolescentes-crianças pobres, das periferias, negros, que lutam por trabalho, por escola pública, por vida. As justificativas das violências de Estado para seus extermínios alegam que eles são adolescentes-jovens de extrema periculosidade. São criminosos, ameaçam a ordem pública. Até como adolescentes são pensados em conflito com a lei.

Um olhar inferiorizante, segregador da sociedade, do Estado, da cultura política que tende a contaminar a visão, a cultura pedagógica, escolar e docente, condenando-os, reprovando-os como violentos, indisciplinados. Aumenta o número de escolas, de educadores que vê esses educandos como vítimas das brutais violências da sociedade, do Estado e dos órgãos de segurança. Suas indisciplinas sociais e escolares são apenas resistências às violências brutais que padecem.

O pensamento pedagógico é obrigado a se colocar uma pergunta: como a dialética desumanização-humanização é deslocada pela institucionalização da opressão-repressão-extermínio-não humanização que orienta as políticas de repressão-extermínio de violência de Estado? A função encomendada à pedagogia desde suas origens é: superar, corrigir 
a desumanização e, pela educação, humanizar os ainda não humanos, não cidadãos. Com isso, a educação para a cidadania, para o trabalho, para a formação humana assumida pelas constituições republicanas e democráticas, perde sentido diante de um Estado e de seus aparelhos justiça, forças da ordem - , pautadas pela repressão, pelo extermínio dos jovens, adolescentes, até crianças não que não são reconhecidos como educáveis, humanizáveis, nem sequer como desumanos-humanizáveis, mas decretados como criminosos, logo, extermináveis.

A dialética "desumanização-humanização" que justificou a pedagogia, as políticas de escolarização perdem sentido quando se decretam crianças, adolescentes-jovens como criminosos, irrecuperáveis, extermináveis em nome da preservação da segurança pública e da reintegração da propriedade da terra. Logo, a ação pedagógica de socialização, moralização, reeducação é dispensada como inútil. Nessa criminalização dos oprimidos não há lugar para a função ético-política da dialética "educar para superar a desumanização e incluir na humanização”.

Diante desse decretar o não-lugar, a não-função da éticapolítica de pedagogia na dialética desumanização-humanização, questões radicais demandam que o pensamento pedagógico se repense. Entender que milhões de seres humanos, inclusive jovensadolescentes e crianças, são submetidos a novos processos de segregação, repressão, extermínio exige ir além de pensar as políticas socioeducativas como mecanismos de educar para humanizar. Exige repensar a função social, política, pedagógica das escolas, da docência, do sistema escolar: ser espaços-tempos de proteção de vidas ameaçadas de extermínios. Os profissionais das escolas públicas e, sobretudo, da EJA, aonde chegam os adolescentes e adultos ameaçados no viver, sobreviver, perguntam-se qual seu ofício, qual a função da docência: proteger vidas ameaçadas? Não é essa a esperança que nós, educadores, e as mães depositam? E os educandos?

Essa é a indagação política-pedagógica-ética que tantos educadores e educadoras se colocam. Uma indagação radical para o pensamento pedagógico, para os currículos de Pedagogia e Licenciatura: que acúmulo de teoria produzir para que os profissionais com a função de cuidar de milhões de proibidos de ser desde a infância, roubados de sua humanidade e até ameaçados de extermínio entendam e acompanhem esses processos? Reconheçamos que há uma lacuna histórica de teoria pedagógica sobre os históricos processos de roubar humanidades, de proibi-los de ser humanos, de se saberem- roubados em seu direito à vida. Essa lacuna exige ser preenchida com toda urgência. 


\section{$6^{\circ}$. ) OS OPRIMIDOS RESISTEM, AFIRMAM-SE HUMANOS}

Paulo Freire se pergunta pela função da pedagogia, dos profissionais da educação no acompanhar educandos roubados em suas humanidades: responsabilizá-los da opressão que padecem? Conscientizá-los? Não vê os oprimidos como inconscientes desse assalto, condenados a vivências de desumanização e de extermínios. Lembra-nos: "quem melhor que os oprimidos se encontrará preparado para entender o significado terrível de uma sociedade opressora? Quem sentirá melhor que eles os efeitos da opressão?” (FREIRE, 1987, p. 31).

A pedagogia, até a crítica, tem insistido que sua função é conscientizar os oprimidos dos significados da sociedade opressora. Paulo aponta para uma tarefa mais radical: reconhecer os próprios oprimidos preparados para entender os significados de uma sociedade opressora, de um Estado opressor, porque ninguém melhor que eles sente os efeitos do autoritarismo.

A função dos cursos de formação de docentes educadores será prepará-los para entender com os oprimidos os significados da sociedade opressora e do Estado opressor; compreender suas consciênciassaberes de experiências de opressão; e, sobretudo, conhecer suas resistências aos efeitos desumanizantes da opressão que padecem. Logo, é preciso formar para entender com prioridade os processos de desumanização e seu efeito mais radical: roubar as humanidades desses sujeitos. Paulo nos convida a ir além. Reconhecer os processos históricos de desumanização, de roubo de suas humanidades, que milhões de oprimidos padecem é, para Freire, um desafio radical para a pedagogia e a docência. Mas ele ainda nos desafia a nos conscientizar das resistências e das lutas dos oprimidos por justiça, por liberdade, pela recuperação de sua humanidade roubada, pelo direito à vida justa.

Para Paulo, a tarefa do pensamento pedagógico e dos educadores de milhões de educandos que, desde a infância, padecem a opressão é reconhecê-los sujeitos resistentes nos processos de libertação-humanização-emancipação. É perceber os educandos oprimidos como sujeitos, desde crianças, de lutas pela humanização, pelo trabalho livre, pela desalienação, por sua afirmação como pessoas, como "seres para si" (FREIRE, 1987, p. 30). Que política educativa, que formação de docentes-educadores é capaz de entender os educandos roubados em suas humanidades, mas resistentes em lutas pela humanização, pela recuperação das humanidades roubadas e pela continuidade de suas vidas?

Paulo se contrapõe às políticas socioeducativas generosas, compassivas de sua condição de oprimidos, de roubados em sua 
humanidade. Denuncia a fraqueza dessas políticas socioeducativas que apenas tentam corrigir os brutais processos de opressão-desumanização que produzem as políticas e estruturas de apropriação-expropriação da terra, do trabalho, da renda, da moradia, da saúde, da vida.

Paulo enfatiza que aqueles que oprimem, exploram, violentam, em razão de seu poder, não podem ter, nesse poder, a força de libertação dos oprimidos. O Estado perdeu sua função protetora e libertadora dos oprimidos. Só o poder que nasça da debilidade dos oprimidos será suficientemente forte para libertá-los. Freire sugere que a função da pedagogia, da docência, será fortalecer essa debilidade dos oprimidos para fortificar sua liberação, emancipação.

Paulo Freire critica esse traço tão persistente das políticas socioeducativas inclusivas, corretivas das desumanidades dos oprimidos. Critica as políticas e o poder dos opressores que, quando pretendem amenizar a debilidade dos oprimidos, não apenas quase sempre se expressam em falsa generosidade, mas também jamais a ultrapassam. Lembra-nos de que os opressores, falsamente generosos, têm a necessidade que sua "generosidade" continue tendo oportunidade de realizar-se, que a injustiça permaneça. A “ordem” social injusta é a fonte geradora, permanente, dessa "generosidade" que se nutre da morte, do desalento e da miséria (FREIRE, 1987, p. 31).

Essa crítica política radical de Paulo Freire dirige-se a tantas políticas socioeducativas corretivas, inclusivas, generosas, destinadas às infâncias-adolescências das escolas públicas, da EJA e até dos centros socioeducativos de adolescentes privados de liberdade. Voltase a tantas diretrizes de formação de docentes-educadores nas artes de implementar políticas de falsa generosidade, de inclusão compassiva, corretiva. Essas políticas ocultam a permanência das injustiças que educandos e educadores padecem. Escondem as violências de Estado, de seus aparelhos da ordem e até da justiça, que levam a repressão aos oprimidos e conduzem a processos brutais de extermínios. Nestes novos-velhos tempos, as violências de Estado não se limitam a colocar os oprimidos à margem, mas os decretam extermináveis, porque são negros, militantes, mulheres líderes, assim como Marielle. Não há mais lugar para políticas inclusivas, compassivas com os oprimidos.

A esse paradigma pedagógico compassivo hegemônico tão persistente e a essas violências de Estado, Paulo Freire contrapõe a Pedagogia do Oprimido: aquela pedagogia que tem de ser forjada com ele e não para ele, considerando os Outros enquanto homens e povos, classes, na luta incessante de recuperação de sua humanidade, de preservação de suas vidas. Essa pedagogia faz da opressão e 
de suas causas objeto da reflexão dos oprimidos, de que resultará o engajamento necessário na luta por sua libertação, com que essa pedagogia se fará e refará (FREIRE, 1987, p. 32).

\section{$7^{\circ}$.) OUTRO PARADIGMA DE FORMAC̣ÃO DE DOCENTES-EDUCADORES?}

Neste texto, acompanhou-nos a hipótese de que Paulo Freire nos aponta para Outro Paradigma Pedagógico. Poderia terminar com uma pergunta: aponta-nos, realmente, para outro paradigma de formação de docentes-educadores? Que dimensões da sua formação para entender, acompanhar, para fortalecer os educandos vítimas de tantas opressões e para fortificar suas resistências por emancipação da opressão? Por direito à vida? Elenco algumas possibilidades:

- Produzirmais teorias sobre os processos de desumanização.

- Formar educadores para entender educandos roubados em suas humanidades.

- Compreender as violências de Estado que os ameaçam de extermínios.

- Reconhecer os próprios oprimidos sujeitos de resistências, libertação, emancipação.

- Reforçar o direito a saberem-se roubados em suas humanidades, mas lutando para se afirmar humanos, para recuperar suas humanidades roubadas, para preservar suas vidas ameaçadas.

São tempos de repolitizados processos de opressão. São tempos de reaprender com Paulo Freire o que ele aprendeu: deixarnos interrogar pelos Oprimidos, por suas Pedagogias de Oprimidos. É o momento de aprender que os Oprimidos resistem à opressão e, resistindo, humanizam-se, educam-se, educam o Estado opressor, a política, a sociedade opressora, o pensamento pedagógico, a Educação. Como educadores e educadoras, deixemo-nos não só interrogar, deixemo-nos educar pelos Oprimidos.

\section{REFERÊNCIAS}

ARROYO, M. G. Imagens quebradas: trajetórias e tempos de alunos e mestres. Petrópolis: Vozes, 2004.

Outros Sujeitos, Outras Pedagogias. Petrópolis: Vozes, 2012.

. O humano é viável? É educável? Revista Pedagógica, Chapecó, v.17, p. 21-40, 2015. 
BENJAMIN, W. Magia e técnica, arte e política: ensaios sobre literatura e história da cultura. São Paulo: Brasiliense, 1994.

FREIRE, P. Pedagogia do oprimido. Rio de Janeiro: Paz e Terra, 1987.

QUIJANO, A. Colonialidade do poder e classificação social. In: SANTOS, B.S.; MENEZES, M.P. (org.). Epistemologias do Sul. São Paulo: Cortez, 2009.

SANTOS, B.S.; CHAUÍ, M. Direitos Humanos, Democracia e Desenvolvimento. São Paulo: Cortez, 2013.

WAISELFISZ, J. J. Mapa da Violência: Os jovens no Brasil. Rio de Janeiro: Flacso-Brasil, 2014.

\section{NOTAS}

${ }^{1} \mathrm{O}$ texto é uma reelaboração da abertura do II Congresso Internacional Paulo Freire: O Legado Global, promovido pela Faculdade de Educação da UFMG, no período de 28/04/2018 a 01/05/2018.

Submetido: 26/09/2018

Aprovado: 05/02/2019

Contato:

Miguel Gonzalez Arroyo

Rua Tomé de Sousa, n. 562, ap. 601 - Bairro Funcionários

Belo Horizonte |MG | Brasil

CEP 30.140-130 